\title{
液-液相分离：超分子聚合物成核-生长的启动子
}

张希

清华大学化学系, 北京 100084

\section{Liquid-liquid Phase Separation: The Promoter of Nucleation and Growth of Supramolecular Polymers}

\author{
Xi Zhang \\ Department of Chemistry, Tsinghua University, Beijing 100084, P. R. China. \\ Email: xi@mail.tsinghua.edu.cn. \\ Published online: April 2, 2020.
}

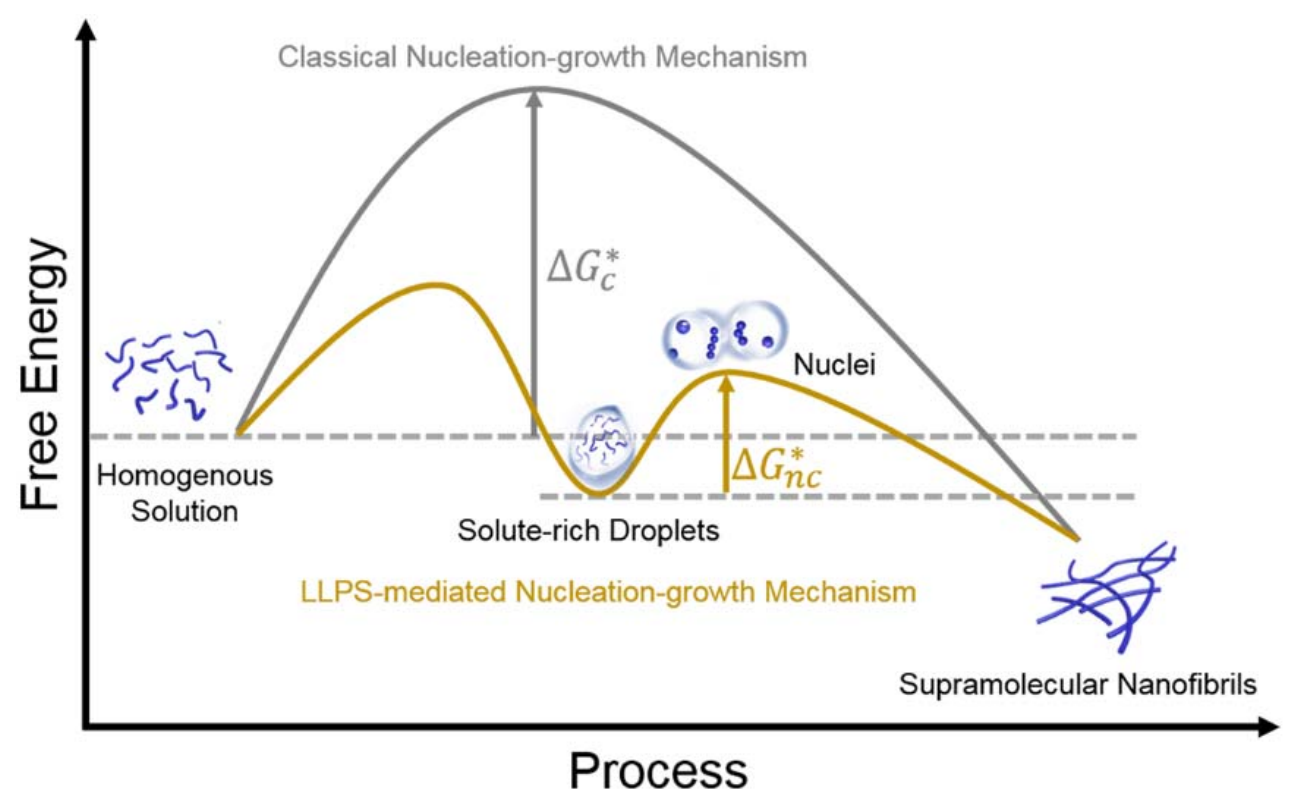

液-液相分离介导的超分子聚合物成核-生长。

超分子聚合物普遍存在于自然界, 尤其是生 物体中，如细胞骨架的重要组成部分微管和蛋白 质细丝等 ${ }^{1-3}$ 。生物分子从溶液状态到超分子聚合 物的结构转变, 不仅发挥着生物体的某些特定功 能, 也与一些疾病的发生密切相关 ${ }^{4}$ 。因此对超分 子聚合物形成机制的研究, 不仅有助于加深对生 物体结构与功能的认知, 促进相关疾病新型治疗 策略的开发, 也为复杂仿生体系的设计和构建提 供了新思路。

一般来说, 超分子聚合物的形成包含成核和
生长两个阶段。作为溶液中新相形成的初始孕育 阶段, 成核对超分子聚合物的结构和性质具有至 关重要的作用。尽管已有相关的研究表明, 蛋白 质、无机纳米晶和胶体自组装的成核可以通过经 典的单步成核或者由亚稳相参与的两步成核来实 现 ${ }^{5-7}$ 。然而, 对生物小分子的超分子成核机制及其 在后续生长中作用的研究仍是一大挑战。这是由 于生物小分子的柔性构象和远程弱相互作用使其 在快速成核过程中产生大量多分散的瞬态中间 体, 极大地限制了对成核过程的追踪监测 ${ }^{8}$ 。因此, 
选取合适的组装基元，通过对其分子间相互作用 和成核动力学的调控, 有望揭示复杂体系中超分 子聚合物的成核-生长机制。

近日, 中国科学院过程工程研究所闰学海研 究员与剑桥大学Tuomas P. J. Knowles教授合作, 选取双亲性的寡肽和氨基酸为研究模型, 通过引 入配位作用或调节溶剂组成来增强组装基元间的 相互作用, 以提高成核中间体的稳定性, 并结合冷 冻电镜和生物分子的自体荧光成像, 实现了对超 分子纳米纤维形成过程的有效追踪。研究发现, 液-液相分离是超分子纳米纤维成核的启动子, 所 形成的富含溶质液滴是分子聚集成核的“小 室” ${ }^{9}$ ，表明超分子成核是一个由亚稳态液滴参与 的多步成核过程。研究者对该过程进行了原位核 磁和热力学研究, 发现疏水作用主导的液滴形成 是一个熵驱动的过程; 而氢键作用主导的液滴到 纳米纤维的转变是一个焓驱动的过程。与经典成 核相比, 相分离液滴的出现显著降低了超分子纳 米纤维的成核势垒。

上述研究工作近期在 Angewandte Chemie International Edition 上在线发表 9 。该工作揭示了 超分子纳米纤维形成过程中液-液相分离介导的 多步成核新机制, 回答了 “成核点从何而来” 这一 关键问题, 通过对相分离液滴的控制有望实现更 精准的超分子自组装。值得指出的是, 液-液相分 离作为一种生物分子的组织模式对多种生理功能 的发挥具有重要的调控作用 ${ }^{10}$, 因此, 该工作将为 我们更深入理解生命起源奥秘和探索相关疾病治
疗策略提供了新的启示。

\section{References}

(1) Aida, T.; Meijer, E. W.; Stupp, S. I. Science 2012, 335, 813. doi: $10.1126 /$ science. 1205962

(2) Yang, L.; Tan, X.; Wang, Z.; Zhang, X. Chem. Rev. 2015, 115, 7196. doi: $10.1021 / \operatorname{cr} 500633 b$

(3) Yin, Z.; Song, G.; Jiao, Y.; Zheng, P.; Xu, J. -F.; Zhang, X. CCS Chem. 2019, 1, 335. doi: 10.31635/ccschem.019.20190013

(4) Iadanza, M. G.; Jackson, M. P.; Hewitt, E. W.; Ranson, N. A.; Radford, S. E. Nat. Rev. Mol. Cell Biol. 2018, 19, 755. doi: 10.1038/s41580-018-0060-8

(5) Wolde, P. R. T.; Frenkel, D. Science 1997, 277, 1975. doi: $10.1126 /$ science. 277.5334 .1975

(6) Loh, N. D.; Sen, S.; Bosman, M.; Tan, S. F.; Zhong, J.; Nijhuis, C. A.; Král, P.; Matsudaira, P.; Mirsaidov, U. Nat. Chem. 2017, 9, 77. doi: $10.1038 /$ nchem. 2618

(7) Tan, P.; Xu, N.; Xu, L. Nat. Phys. 2013, 10, 73. doi: $10.1038 /$ nphys 2817

(8) Van Driessche, A. E. S.; Van Gerven, N.; Bomans, P. H. H.; Joosten, R. R. M.; Friedrich, H.; Gil-Carton, D.; Sommerdijk, N. A. J. M.; Sleutel, M. Nature 2018, 556, 89. doi: 10.1038/nature25971

(9) Yuan, C.; Levin, A.; Chen, W.; Xing, R.; Zou, Q.; Herling, T. W.; Challa, P. K.; Knowles, T. P. J.; Yan, X. Angew. Chem. Int. Ed. 2019, 58, 18116. doi: 10.1002/anie.201911782

(10) Banani, S. F.; Lee, H. O.; Hyman, A. A.; Rosen, M. K. Nat. Rev. Mol. Cell Biol. 2017, 18, 285. doi: 10.1038/nrm.2017.7 